\title{
Effect of Serum Amyloid A on Cellular Affinity of Low Density Lipoprotein
}

\author{
Toshiyuki Yamada ${ }^{1}$, Takashi Miida ${ }^{2}$, Tetsuji Yamaguchi ${ }^{1}$ and Yoshihisa Itoh ${ }^{1}$ \\ 1 Department of Clinical Pathology, Jichi Medical School, Tochigi, Japan \\ 2 Department of Laboratory Medicine, Niigata University School of Medicine, Niigata, Japan
}

Summary: Serum amyloid A, an apolipoprotein of high density lipoproteins, is also present to a lesser degree in low density lipoproteins and is co-localized with apolipoprotein B in atherosclerotic lesions. This study examined the effect of serum amyloid $\mathrm{A}$ on cellular affinity of low density lipoprotein in vitro. ${ }^{125}$ I-labelled low density lipoprotein, when loaded with recombinant serum amyloid A1 (acute phase isotype) or recombinant serum amyloid A4 (constitutive isotype), had enhanced binding to both human skin fibroblasts and a murine macrophage cell line, J774, while its degradation was slightly increased in both cells. The binding of oxidized low density lipoprotein to J774 cells was also enhanced by addition of recombinant serum amyloid A1 or serum amyloid A4, and degradation of oxidized low density lipoprotein was moderately enhanced by recombinant serum amyloid A1. The effects of recombinant serum amyloid A on cellular binding of labelled low density lipoprotein were not competed by nonlabelled low density lipoprotein and were diminished in the presence of high density lipoprotein. These findings suggest that serum amyloid $\mathrm{A}$ in low density lipoprotein may promote association of low density lipoprotein with cells by non-specific adsorption, and high density lipoprotein may prevent such interactions by removal of serum amyloid $\mathrm{A}$.

\section{Introduction}

Serum amyloid $A$ is the putative serum precursor of amyloid $\mathrm{A}$, the main fibrillar constituent in reactive amyloid deposits $(1,2)$. The serum amyloid A protein family in humans consists of six genetically determined isotypes (serum amyloid $\mathrm{A} 1 \alpha, 1 \beta, 1 \gamma, 2 \alpha, 2 \beta$, and 4) $(2-5)$. They are classified into two groups based on the regulation of their synthesis. One group are the acute phase isotypes including serum amyloid A1 and 2 whose serum level is markedly increased during inflammation $(2,6)$. Acute phase serum amyloid $\mathrm{A}$ has been proposed to be involved in several inflammatory events, such as leukocyte chemotaxis (7), induction of collagenase (8) and inhibition of platelet agglutination (9). The other isotype, constitutive serum amyloid A (serum amyloid A4), does not behave like acute phase reactants or form amyloid fibrils $(4,10,11)$.

Serum amyloid A proteins are associated primarily with high density lipoproteins $(4,12)$, and only a little with other lipoproteins in circulation (13-15). In inflammatory states, high density lipoprotein greatly changes its composition; increased serum amyloid A, reduced cholesterol, and reduced apolipoprotein A-I (16). Recently, greater attention has been focussed on the roles of acute phase serum amyloid A or high density lipoproteins rich in acute phase serum amyloid A in lipoprotein metabolism. Putative biological functions include reduction of lecithin:cholesterol acyltransferase activity (17), en- hancement of the affinity of high density lipoprotein to macrophages (18), involvement in binding cholesterol (19), reduction of high density lipoprotein-mediated cellular cholesterol efflux (20), and reduction of the antioxidizing effect of high density lipoprotein on low density lipoprotein (21). Some of these activities may suggest preventative effects of acute phase serum amyloid A against atherogenesis, whereas others may suggest promotive effects. No particular function has been proposed for serum amyloid A4.

Both serum amyloid A isotypes have been detected in human atherosclerotic lesions (22). The distribution of serum amyloid $\mathrm{A}$ in the lesions was identical with that of apolipoprotein B, the major protein component of low density lipoproteins. These findings led us to hypothesize that serum amyloid A bound to low density lipoprotein may affect the uptake of low density lipoprotein by the cells involved in atherogenesis. In this study, changes in cellular affinity of low density lipoprotein when loaded with serum amyloid $\mathrm{A}$ in vitro were investigated.

\section{Materials and Methods \\ Preparation of lipoproteins and recombinant serum amyloid $\mathrm{A}$}

Low density lipoproteins (d 1.006-1.063 kg/l) and high density lipoproteins (d $1.063-1.21 \mathrm{~kg} / \mathrm{l})$ were prepared from plasma of healthy adults by ultracentrifugation according to the method of 
Hatch and Lee (23). They were dialyzed against $10 \mathrm{mmol} / \mathrm{l}$ phosphate buffered saline, $\mathrm{pH}$ 7.2. Low density lipoprotein was iodinated $\left({ }^{125} \mathrm{I}\right)$ using a lactoperoxidase labelling kit (ICN Biomedicals, Costa Mesa, CA, USA). Mean specific activity was approximately 2000 counts/min $\times$ mg of low density lipoprotein. Recombinant human serum amyloid $\mathrm{Al} \alpha$ and 4 were prepared as previously described (11) and solubilized with $50 \mathrm{mmol} / 1$ sodium bicarbonate, pH 8.0. Protein concentration was determined by the dye-binding method using a commercial kit (Bio-Rad Laboratories, Hercules, CA, USA).

Association of serum amyloid A to low density lipoprotein

Recombinant serum amyloid A $(100 \mathrm{~g} / \mathrm{l})$ was added to ${ }^{125} \mathrm{I}$-labelled low density lipoprotein $(100 \mathrm{~g} / \mathrm{l})$ to yield final concentrations of $0.1,1$, and $10 \mu \mathrm{g}$ recombinant serum amyloid $\mathrm{A}$ per $\mathrm{mg}$ of low density lipoprotein just before cellular binding or degradation experiments. For control (referred to as $0 \mu \mathrm{g}$ recombinant serum amyloid A per mg of low density lipoprotein), $10 \mu \mathrm{g}$ of bovine serum albumin were added per $\mathrm{mg}$ of low density lipoproteins. In separate experiments to determine the amount of added recombinant serum amyloid A incorporated into low density lipoprotein, the recombinant serum amyloid $\mathrm{A}$ and low density lipoprotein mixture were immediately fractionated by gel filtration chromatography using consecutive columns of Superose 6 and Superose 12 (Pharmacia Biotech, Uppsala, Sweden) as previously described (15). The amount of serum amyloid $A$ in each fraction was measured by an enzyme-linked immunosorbent assay $(10,24)$.

\section{Oxidation of low density lipoprotein}

${ }^{125} \mathrm{I}$-labelled low density lipoprotein was incubated with $5 \mu \mathrm{mol} / 1$ $\mathrm{CuCl}_{2}$ for 12 hours at room temperature, and immediately used for the experiments.

\section{Cell cultures}

Human skin fibroblasts were obtained from healthy adults and maintained in fetal calf serum (volume fraction 0.1)-DMEM (Dainippon Pharmaceuticals, Osaka, Japan) at $37^{\circ} \mathrm{C}$ in $5 \% \mathrm{CO}_{2}$. Cells between passages 10 and 20 were used in experiments. Murine macrophage-like cell line J774 was obtained from the American Type Culture Collection and maintained in the same conditions as above. For determination of total cellular protein, cells were extensively washed with fetal calf serum-free DMEM, solubilized in $2 \mathrm{~mol} / \mathrm{l}$ urea, $10 \mathrm{mmol} / 1$ Tris- $\mathrm{HCl}, 0.5 \mathrm{~g} / 1$ Tween $20, \mathrm{pH} 8.0$, and subjected to the dye-binding protein assay as above.

\section{Cellular binding and degradation assay}

Cellular binding and degradation of ${ }^{125}$ I-labelled low density lipoprotein were determined by the method of Goldstein and Brown (25). Confluent fibroblasts in well dishes (diametre: $5 \mathrm{~cm}$ ) were placed in culture medium with lipoprotein-depleted fetal calf serum (volume fraction 0.1)-DMEM and maintained for 12-15 hours. For binding studies, the cells were washed with DMEM and then incubated with $1.5 \mathrm{ml}$ of DMEM containing $10 \mathrm{mg} /{ }^{125} \mathrm{I}$-labelled low density lipoprotein (with or without serum amyloid A loading) for 2 hours at $4{ }^{\circ} \mathrm{C}$. The cells were washed 3 times with DMEM and harvested with $100 \mathrm{mmol} / 1 \mathrm{NaOH}$. The bound radioactivity was measured in a gamma counter. For degradation studies, the cells were incubated with $20 \mathrm{mg} / \mathrm{l}^{125} \mathrm{I}$-labelled low density lipoprotein in $2 \mathrm{ml}$ of fetal calf serum (volume fraction 0.02)-DMEM for 12 hours at $37^{\circ} \mathrm{C}$ in $5 \% \mathrm{CO}_{2}$. The culture media were treated with $100 \mathrm{~g} / 1$ trichloroacetic acid for $30 \mathrm{~min}$ at $4{ }^{\circ} \mathrm{C}$. After centrifugation, the supernatants containing trichloroacetic acid soluble ${ }^{125} \mathrm{I}-\mathrm{la}-$ belled degradation products were extracted with chloroform as previously described (25) and counted. Cellular binding and degradation experiments were also performed with $\mathbf{J 7 7 4}$ cells the same way as for fibroblasts. The data were corrected for non-specific binding or degradation obtained from an assay without cells. Results were expressed as ng bound or degraded low density lipoprotein per mg cellular proteins. All experiments were performed in triplicate. Data were analyzed using the Student's t-test.

\section{Results}

\section{Incorporation of recombinant serum} amyloid A to low density lipoprotein

Gel filtration analysis revealed that the vast majority of recombinant serum amyloid $A$ after incubation with low density lipoprotein $(1 \mu \mathrm{g}$ of serum amyloid A per $\mathrm{mg}$ of low density lipoprotein) was eluted at the position corresponding to low density lipoprotein, a little at the void volume (possibly self-aggregated forms), and negligible amounts in lower molecular mass areas (fig. 1). Serum amyloid A-loaded low density lipoproteins had the same electrophoretic mobility as normal low density lipoprotein on agarose gel electrophoresis (fig. 1 inset).

\section{Binding of recombinant serum amyloid A-low density lipoprotein to fibroblasts}

Both serum amyloid A isotypes associated with ${ }^{125} \mathrm{I}$ labelled low density lipoprotein increased binding of labelled low density lipoprotein to fibroblasts in a dosedependent and saturable fashion (fig. 2). Binding of labelled low density lipoprotein was not effectively reduced under the presence of excess amount of non-labelled low density lipoprotein, suggesting that the enhanced binding was not receptor-mediated when recombinant serum amyloid A was on low density lipoprotein. In addition, there was no difference in competitive effects between low density lipoprotein and recombinant serum amyloid A-loaded low density lipoprotein when added to the low density lipoprotein binding assay (fig. 3).

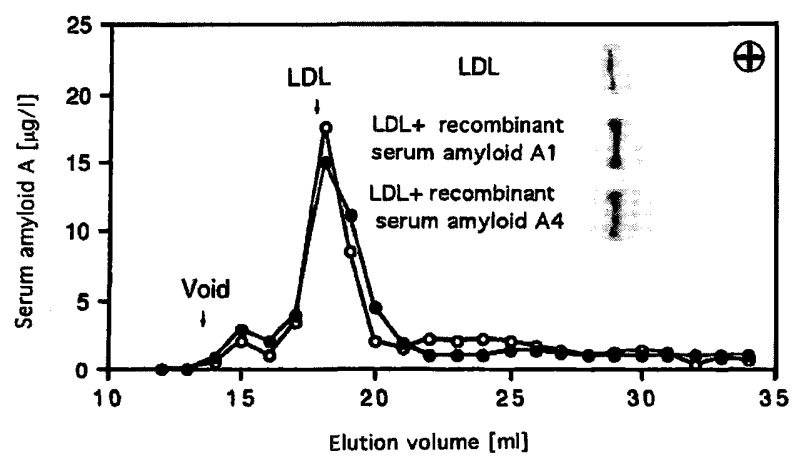

Fig. 1 Incorporation of recombinant serum amyloid A into low density lipoprotein. One thousandth volume of recombinant serum amyloid A1 $(\bullet)$ or serum amyloid A4 (o) (2 g/l) was added to low density lipoprotein (LDL) $(2 \mathrm{~g} / \mathrm{l})$ yielding a final ratio of $1 \mathrm{ng}$ serum amyloid A per mg of LDL. Fifty $\mu \mathrm{l}$ was chromatographed on 2 consecutive columns of Superose $6(2 \times 30 \mathrm{~cm})$ and Superose $12(2 \times 30 \mathrm{~cm})$ equilibrated and eluted with phosphate buffered saline at a flow rate of $0.5 \mathrm{ml} / \mathrm{min}$. Fractions of $0.25 \mathrm{ml}$ were collected and analyzed for acute phase serum amyloid A or serum amyloid A4 by ELISA. The elution positions of lipoproteins were determined previously (15). Agarose gel electrophoresis for LDL and serum amyloid A-incorporated LDL is shown in the inset. 

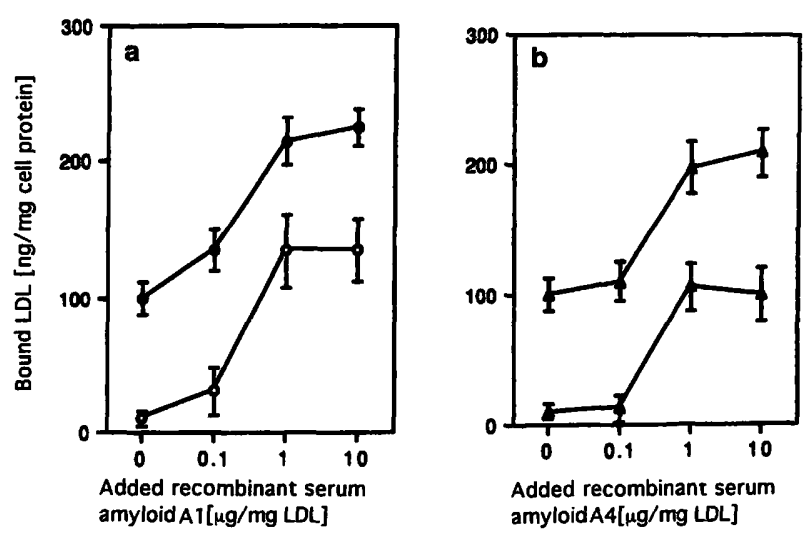

Fig. 2 Binding of recombinant serum amyloid A-loaded low density lipoprotein to fibroblasts (a: serum amyloid Al, b: serum amyloid A4). Cells were incubated with recombinant serum amyloid

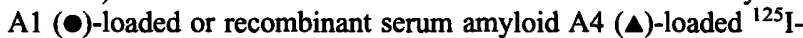
labelled low density lipoprotein (LDL) $(10 \mathrm{mg} / \mathrm{l})$, and bound radioactivity was determined as described in Materials and Methods. Experiments were also performed in the presence of $500 \mu \mathrm{g}$ nonlabelled LDL ( $\circ$; recombinant serum amyloid A1-LDL, $\triangle$; recombinant serum amyloid A4-LDL). Data are shown as means $\pm \mathrm{S}$. E.

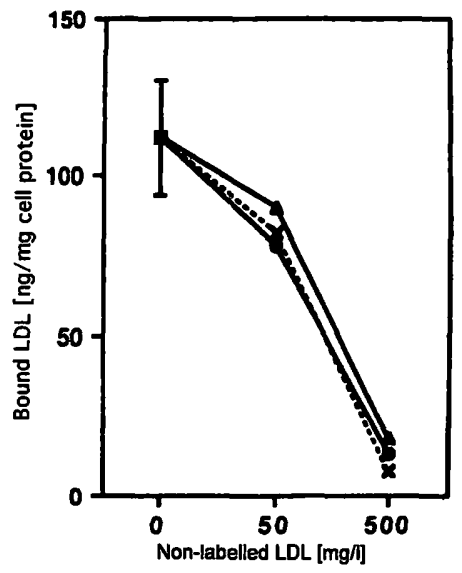

Fig. 3 Binding of recombinant serum amyloid A-loaded low density lipoprotein to fibroblasts in the presence of normal low density lipoprotein. Cells were incubated with $10 \mathrm{mg} /{ }^{125} \mathrm{I}$-labelled low density lipoprotein (LDL) in the presence of 0,50 , or $500 \mathrm{mg} / 1$ non-labelled LDL (x), recombinant serum amyloid A1-loaded LDL $(\bullet)$, or recombinant serum amyloid A4-loaded LDL $(\Delta)(1 \mu \mathrm{g}$ recombinant serum amyloid A per mg of LDL), and bound radioactivity was determined. Data are shown as means. For clarity, S. E. is shown only for the result without non-labelled LDL. The magnitude of S.E. for the data with non-labelled LDL present was about the same.

Binding of recombinant serum amyloid A-low density lipoprotein to J774 cells

Similar to the results from the experiments on fibroblasts, both recombinant serum amyloid A isotypes increased the binding of low density lipoprotein to J774 cells in a dose-dependent and non-specific manner (fig. 4). Oxidized low density lipoprotein had a greater affinity for the cells than non-oxidized low density lipoprotein, and both recombinant serum amyloid $\mathrm{A}$ enhanced the cellular bindings of oxidized low density lipoprotein in a dose-dependent and non-specific manner (fig. 5).
Effect of high density lipoprotein on the cellular bindings of recombinant serum amyloid A-loaded low density lipoprotein

The enhancement of low density lipoprotein binding to fibroblasts by both recombinant serum amyloid $\mathrm{A}$ isotypes was essentially abolished when high density lipoprotein isolated from a healthy subject was included in the incubation mixture of recombinant serum amyloid A-loaded ${ }^{125}$ I-labelled low density lipoprotein and fibroblasts (fig. 6). The enhanced binding of both recombinant serum amyloid A isotype-loaded oxidized low density lipoproteins was also abolished by addition of high density lipoprotein (data not shown). When the recombinant serum amyloid A-low density lipoprotein $(1 \mu \mathrm{g}$ of recombinant serum amyloid A per mg of low density lipoprotein) and high density lipoprotein mixtures were
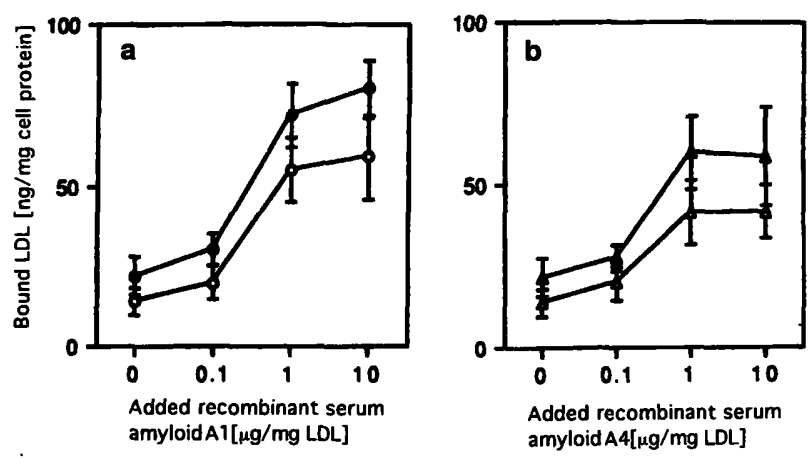

Fig. 4 Binding of recombinant serum amyloid A-loaded low density lipoprotein to $\mathrm{J} 774$ cells (a: serum amyloid $\mathrm{Al}$, b: serum amyloid A4). Cells were incubated with recombinant serum amyloid

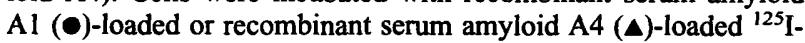
labelled low density lipoprotein (LDL) $(10 \mathrm{mg} / \mathrm{l})$, and bound radioactivity was determined as described in Materials and Methods. Experiments were also performed in the presence of $500 \mu \mathrm{g}$ nonlabelled LDL ( $\circ$; recombinant serum amyloid Al-LDL, $\Delta$; recombinant serum amyloid A4-LDL). Data are shown as means $\pm \mathrm{S}$. E.
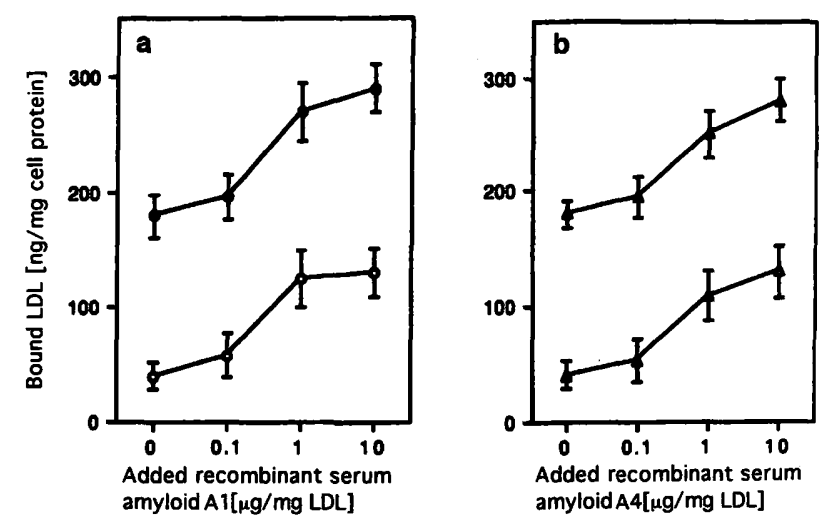

Fig. 5 Binding of recombinant serum amyloid A-loaded oxidized low density lipoprotein to $\mathrm{J} 774$ cells (a: serum amyloid Al, b: serum amyloid A4). Cells were incubated with recombinant serum amyloid A1 (๑)-loaded or recombinant serum amyloid A4 (A)loaded ${ }^{125}$ I-labelled oxidized low density lipoprotein (LDL) (10 $\mathrm{mg} / \mathrm{l}$ ), and bound radioactivity was determined as described in $\mathrm{Ma}-$ terials and Methods. Experiments were also performed in the presence of $500 \mu \mathrm{g}$ non-labelled LDL ( $O$; recombinant serum amyloid Al-LDL, $\Delta$; recombinant serum amyloid A4-LDL). Data are shown as means $\pm \mathrm{S}$. E. 
subjected to gel chromatography, most of the serum amyloid A eluted in the area corresponding to high density lipoprotein (fig. 7).

\section{Degradation of recombinant serum amyloid A-low density lipoprotein in cells}

Recombinant serum amyloid A1- or serum amyloid A4loaded low density lipoprotein was degraded more than normal low density lipoprotein by fibroblasts and J774 cells (tab. 1), but the difference was not statistically significant. Compared to the magnitude of increased cellular binding of recombinant serum amyloid A-low den-

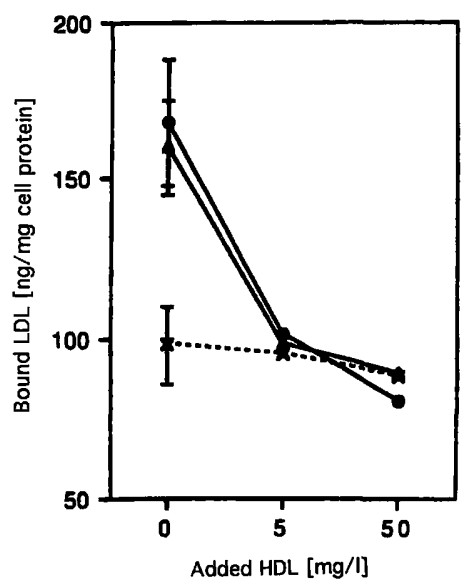

Fig. 6 Effect of high density lipoprotein on binding of low density lipoprotein and recombinant serum amyloid A-loaded low density lipoprotein to fibroblasts. Cells were incubated with $10 \mathrm{mg} / \mathrm{l}$ ${ }^{125}$ I-labelled low density lipoprotein (LDL) $(\mathbf{x})$ or recombinant serum amyloid A1-loaded LDL $(\bullet)$ or recombinant serum amyloid A4-loaded LDL (A) in the presence of various amounts of normal high density lipoprotein. The LDL contained $1 \mu \mathrm{g}$ recombinant serum amyloid Al or recombinant serum amyloid A4 per $\mathrm{mg}$ of LDL. Bound radioactivity was determined as described in Materials and Methods. Data are shown as means. For clarity, S. E. are shown only for the data without high density lipoprotein. The magnitude of S. E. was about the same for the data with high density lipoprotein.

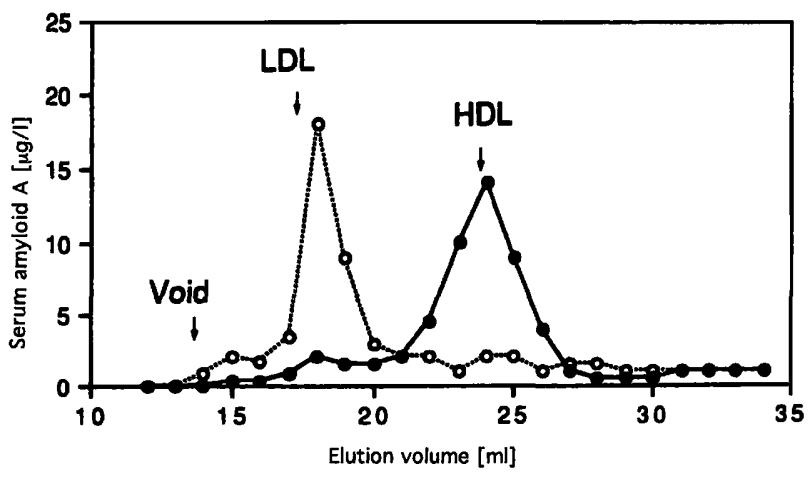

Fig. 7 Transfer of recombinant serum amyloid A1 from low density lipoprotein to high density lipoprotein. Fifty $\mu \mathrm{l}$ of recombinant serum amyloid Al-loaded low density lipoprotein (LDL) (2 g $\mathrm{LDL} / 1,1 \mu \mathrm{g}$ recombinant serum amyloid $\mathrm{A} 1$ per $\mathrm{mg}$ of LDL) before (O) and after (๑) mixing with an equal volume of high density lipoprotein (HDL) ( $2 \mathrm{~g} / 1$ protein) were subjected to gel filtration on consecutive columns of Superose 6 and Superose 12 as described in figure 1 . Fractions were analyzed for serum amyloid A content by ELISA. sity lipoprotein, the amount of degradation appeared low, suggesting that recombinant serum amyloid A-low density lipoprotein bound to the cell surfaces was not significantly internalized. Oxidized low density lipoprotein was degraded more than native low density lipoprotein by J774 cells. Recombinant serum amyloid A1 significantly increased oxidized low density lipoprotein degradation while recombinant serum amyloid $\mathrm{A} 4$ had no effect.

\section{Discussion}

Apolipoproteins are present on every lipoprotein particle. Although serum amyloid $\mathrm{A}$ is primarily associated with high density lipoproteins, a lesser association with other lipoproteins is likely. Indeed, the presence of acute phase serum amyloid A and constitutive serum amyloid A (serum amyloid A4) in low density lipoprotein from inflammatory sera and hypertriglyceridaemic sera, respectively, has been observed $(13,15)$. Such conditions may be related to the promotion of the atherosclerotic diseases $(26,27)$ in which low density lipoproteincholesterol is accumulated in plasma and tissues. We studied the association of serum amyloid A with low density lipoprotein and its possible implications in disorders of lipoprotein metabolism.

We used human skin fibroblasts and a murine macrophage-like cell line, J774, since they have been wellstudied as low density lipoprotein receptor - and scavenger receptor - carrying cells, respectively. Recombinant proteins allowed us to examine the effects of two representative acute phase and constitutive serum amyloid A isotypes on the interaction between low density lipoprotein and cells.

The effect of recombinant serum amyloid A1 or serum amyloid A4 on low density lipoprotein clearly increased binding of low density lipoprotein to both fibroblasts and $\mathbf{J 7 7 4}$ cells. The binding of oxidized low density lipoprotein to J774 cells was also enhanced by both recombinant serum amyloid $\mathrm{A}$ isotypes. When several patient sera were subjected to the same chromatographic separation as in this study followed by serum amyloid $\mathrm{A}$ determinations, both serum amyloid $\mathrm{A}$ isotypes in the peak corresponding to low density lipoprotein were $3 \%$ of those in the high density lipoprotein peak (our unpublished observation). Thus, of the three concentrations of recombinant serum amyloid $A$ examined, 0.1 and $1 \mu \mathrm{g}$ serum amyloid A per mg of low density lipoprotein can occur in circulation, whereas $10 \mu \mathrm{g}$ per $\mathrm{mg}$ low density lipoprotein may be rare. However, the possibility that locally synthesized serum amyloid A (28) may be associated at high concentration with low density lipoprotein cannot be ruled out.

We first speculated that serum amyloid A could alter low density lipoprotein or scavenger receptor-mediated 
Tab. 1 Effect of recombinant serum amyloid A on cellular degradation of ${ }^{125}$ I-labelled low density lipoprotein (LDL).

Tracer
LDL degradation : ng/mg cell proteins

\begin{tabular}{lc}
\hline Fibroblasts & J774 cells \\
\hline $951 \pm 108$ & $117 \pm 12$ \\
$1341 \pm 295$ & $148 \pm 18$ \\
$1095 \pm 167$ & $149 \pm 19$ \\
nd & $2009 \pm 118$ \\
nd & $4581 \pm 151^{*}$ \\
nd & $2178 \pm 92$
\end{tabular}

* $\mathrm{p}<0.05$ vs oxidized LDL without recombinant serum amyloid A.

nd $=$ not determined. binding. However, this is unlikely because neither recombinant serum amyloid A1 or serum amyloid A4 alter electrostatic charges of low density lipoprotein (fig. 1 inset), neither recombinant serum amyloid A1 or serum amyloid A4 affected receptor-mediated cellular binding of low density lipoprotein as indicated by competition experiments (fig. 2), and bound recombinant serum amyloid A-loaded low density lipoprotein were not internalized significantly into cells except for the combination of recombinant serum amyloid A1-loaded oxidized low density lipoprotein and $\mathrm{J} 774$ as indicated by cellular degradation experiments (tab. 1). Thus, both serum amyloid $A$ isotypes enhance non-specific binding of low density lipoprotein to cells possibly by hydrophobic interactions, suggesting that serum amyloid A does not play an active role in low density lipoprotein metabolism in vivo. Enhanced degradation of recombinant serum amyloid A1-loaded oxidized low density lipoprotein by J774 cells was observed. Increased adsorption of oxidized low density lipoprotein to this macrophage-like cell, although non-specific, may facilitate the internalization (phagocytosis) of low density lipoprotein. The absence of a significant effect from recombinant serum amyloid A4-loaded oxidized low density lipoprotein remains to be clarified.

\section{References}

1. Stone MJ. Amyloidosis. A final common pathway for protein deposition in tissues. Blood 1990; 75:531-45.

2. Husby G, Marhaug G, Downton B, Sletten K, Sipe JD. Serum amyloid A (SAA). Biochemistry, genetics and the pathogenesis of AA amyloidosis. Amyloid Int J Exp Clin Invest 1994; $1: 119-37$.

3. Dwulet FE, Wallace DK, Benson MD. Amino acid structures of multiple forms of amyloid-related serum protein SAA from a single individual. Biochemistry $1988 ; 27: 1677-82$.

4. Whitehead AS, de Beer MC, Rits M, Lelias JM, Lane WS, de Beer FC. Identification of novel members of serum amyloid A protein superfamily as constitutive apolipoproteins of high density lipoprotein. J Biol Chem 1992; 267:3862-7.

5. Baba S, Takahashi T, Kasama T, Fujie M, Shirasawa H. A novel polymorphism of human serum amyloid A protein,
High density lipoprotein inhibited the effects of serum amyloid A on low density lipoprotein cellular binding by removing recombinant serum amyloid A from low density lipoprotein, due to the greater affinity of serum amyloid A for high density lipoprotein than low density lipoprotein. To date, numerous studies have used purified or recombinant serum amyloid A to elucidate functions of this protein. In some of these, high density lipoprotein was shown to abolish or reduce the experimental effects of serum amyloid A (7). It has been proposed that serum amyloid A, dissociated from high sensity lipoprotein, may produce harmful effects, such as amyloid fibril formation (11) or promotion of inflammatory reactions (7). Serum amyloid $\mathrm{A}$ on low density lipoprotein may also need to be scavenged by high density lipoprotein to prevent low density lipoprotein or damaged low density lipoprotein from prolonged interactions with cells.

\section{Acknowledgements}

This work was supported by a Grant-in-Aid for Encouragement of Young Scientists (No. 98772184) from the Ministry of Education, Science and Culture of Japan. We thank Prof. Yasushi Saito and Ms. Masako Otabe, Chiba University Medical School, Chiba, Japan, and Dr. Juris J. Liepnieks, Indiana University, Indianapolis, IN, USA, for useful advices and technical support.

SAA1, is characterized by alanines at both residues 52 and 57 . Biochim Biophys Acta 1992; 1180:195-200.

6. Kushner I. The phenomenon of the acute phase response. Ann NY Acad Sci 1982; 389:39-48.

7. Badolato R, Wang JM, Murphy WJ, Lloyd AR, Michiel DF, Bausserman LL, et al. Serum amyloid A is a chemoattractant: induction of migration, adhesion, and tissue infiltration of monocytes and polymorphonuclear leukocytes. J Exp Med 1994; 180:203-10.

8. Mitchell TI, Coon CI, Brinckerhoff CE. Serum amyloid A (SAA3) produced by rabbit synovial fibroblasts treated with phorbol esters or interleukin 1 induces synthesis of collagenase and is neutralized with specific antiserum. J Clin Invest 1991; 87:1177-85. 
9. Zimlichman S, Danon A, Nathan I, Moses G, Shaikin-Kestenbaum $R$. Serum amyloid $A$, an acute phase protein, inhibits platelet activation. J Lab Clin Invest 1990; 116:180-6.

10. Yamada T, Kluve-Beckerman B, Kuster WM, Liepnieks JJ, Benson MD. Measurement of serum amyloid A4 (SAA4). Its constitutive presence in serum. Amyloid Int J Exp Clin Invest 1994; 1:114-8.

11. Yamada T, Kluve-Beckerman B, Liepnicks JJ, Benson MD. Fibril formation from recombinant human serum amyloid $\mathrm{A}$. Biochim Biophys Acta 1994; 1226:323-9.

12. Benditt EP, Eriksen N. Amyloid protein SAA is associated with high density lipoprotein from human sera. Proc Natl Acad Sci USA 1977; 74:4025-8.

13. Marhaug G, Sletten K, Husby G. Characterization of amyloid related protein SAA complexed with serum lipoproteins (apoSAA). Clin Exp Immunol 1982; 50:382-9.

14. de Beer MC, Yuan T, Kindy MS, Asztalos BF, Roheim PS, de Beer FC. Characterization of constitutive human serum amyloid A protein (SAA4) as an apolipoprotein. J Lipid Res 1995; 36:526-34.

15. Yamada T, Miida T, Itoh Y, Kawai T, Benson MD. Characterization of serum amyloid A4 as a plasma lipoprotein. Clin Chim Acta 1996; 251:105-12.

16. Coetzee GA, Strachan AF, van der Westhuyzen DR, Hoppe HC, Jeenah MS, de Beer FC. Serum amyloid A-containing human high density lipoprotein 3: density, size and apolipoprotein composition. J Biol Chem 1986; 261:9644-51.

17. Steinmetz A, Hocke G, Saile R, Puchois P, Fruchart J-C. Influence of serum amyloid $A$ on cholesterol esterification in human plasma. Biochim Biophys Acta 1989; 1006:173-8.

18. Kisilevsky R, Subrahmanyan L. Serum amyloid A changes high density lipoprotein cellular affinity. Lab Invest 1992; 66:778-85.

19. Liang J, Sipe JD. Recombinant human serum amyloid A (apo$\mathrm{SAA}_{\mathrm{p}}$ ) binds cholesterol and modulates cholesterol flux. J Lipid Res 1995; 36:37-46.
20. Banka CL, Yuan T, de Beer MC, Kindy M, Curtiss LK; de Beer FC. Serum amyloid A (SAA): influence on HDL-mediated cellular cholesterol efflux. J Lipid Res 1995; 36:1058-65.

21. Van Lenten BJ, Hama SY, de Beer FC, Stafforini DM, McIntyre TM, Prescott SM, et al. Anti-inflammatory HDL becomes pro-inflammatory during the acute phase response. J Clin Invest $1995 ; 96: 2758-67$.

22. Yamada T, Kakihara T, Kamishima T, Fukuda T, Kawai T. Both acute phase and constitutive serum amyloid $\mathrm{A}$ are present in the atherosclerotic lesions. Pathol Int 1996; 6:797-800.

23. Hatch FT, Lee RS. Practical methods for plasma lipoprotein analysis. Adv Lipid Res 1968; 6:2-68.

24. Yamada $T$, Uchiyama $K$, Yakata $M$, Gejyo F. Sandwich enzyme immunosassay for serum amyloid A protein (SAA). Clin Chim Acta $1989 ; 179: 169-76$

25. Goldstein JL, Brown MS. Binding and degradation of low density lipoproteins by cultured human fibroblasts. J Biol Chem 1974; 249:5153-62.

26. Wolfe F, Mitchell DM, Sibley JT, Fries JF, Bloch DA, Williams CA, et al. The mortality of rheumatoid arthritis. Arthritis Rheum 1994; 37:481-94.

27. Castelli WP. The triglyceride issue: a view from Framingham. Am Heart J 1986; 112:432-7.

28. Meek RL, Urieli-Shoval S, Benditt EP. Expression of apolipoprotein serum amyloid A mRNA in human atherosclerotic lesions and cultured vascular cells. Implications for serum amyloid A function. Proc Natl Acad Sci USA 1994; 91:3186-90.

\section{Received January 27/April 14, 1997}

Corresponding author: T. Yamada, M.D., Department of Clinical Pathology, Jichi Medical School, Minamikawachimachi, Tochigi 329-04, Japan

Fax: +285-44-9947 